\title{
Improving Auto Insurance Course Teaching through Case Study
}

\author{
Yali Yang ${ }^{1, a}$, Renhong Juan ${ }^{1, b}$, Hao Chen ${ }^{1, c,{ }^{*}}$ \\ ${ }^{1}$ College of Automotive Engineering, Shanghai University of Engineering Science, Shanghai, \\ 201620 \\ aemail: carolyn71@163.com, bemail:ren-hongjuan@163.com, cemail:pschenhao@163.com \\ ${ }^{*}$ Corresponding author
}

\section{Keywords: Auto Insurance; Teaching; Case Study}

\begin{abstract}
Auto Insurance Course is a market oriented course, with close relation with market and industry. Case study method is a useful way to improve the ability of utilizing knowledge to solve actual problem, and enhance the career competence and ability. Based on the characteristics of the course and case study method, the method to incorporating case study in course teaching is established, thus to improve the ability of theoretical and practical knowledge to solve the actual auto insurance and claim related problems, to enhance the development of auto industry in China.
\end{abstract}

\section{Introduction}

With rapid development in economy, auto population maintains rapid development in China. Consequently, demand for auto insurance is growing. On an average, premiums of China auto insurance industry amounts to over 60 percent of aggregate premiums of insurance industry of China. China automobile insurance industry is a major contributor in non life insurance segment. It is also regarded as having best rate of growth among all insurance industries of China[1]. However, the development of auto insurance industry is restricted due to the lack of specialized personnel. Under this circumstance, auto industry course is started in many colleges in China for auto industry related majors.

Auto Insurance Course has combined knowledge with theory and practice, which cultivate students' ability in auto evaluation, auto testing, accident survey and loss assessment. Thus, this course combines many auto related contents, which is quite hard to comprehend thoroughly. And most auto related majors' student is the first time to know about the auto insurance knowledge. The ability in auto insurance theory application to analysis and solve real issue should be cultivated in this course. As a practice-oriented course, strong collection between theory and practice teaching is required. Case method is a very important method to improve the interest of students, and integrate theory and practice, thus to improve the ability of utilizing knowledge to solve actual problem. Therefore, this paper probed into the using of case method in the teaching of Auto Insurance Course, to enhance the teaching result and students' ability[2].

\section{Features of case method teaching}

Cases compel students to work on real world problems that are complicated and messy. Those complications force students to hone their skills in finding and using evidence, choosing which concepts, theories and methods are relevant, and ignoring extraneous and irrelevant material, no matter how interesting it may seem.

Written cases are longer than most other kinds of active learning exercises and take more time for students to prepare and for classes to discuss. Cases often have many parts and reflect many points of view, require analyses that involve several steps and involve a variety of kinds of intellectual tasks. The decisions to be made in case analysis push students closer to the top of Bloom's pyramid, since they involve synthetic and evaluative activities.

Case discussions, in the whole class or in small groups, help students learn effective listening and response skills, push them to present clear and reasoned arguments and enhance public speaking skills. They provide an opportunity for students to learn from each other, which give them the opportunity to take ownership of their learning. From the faculty perspective, case discussion 
provides a great opportunity for on-the-spot assessment of student learning, since the discussion reveals information about individual student's mastery as well as a sense of the gaps in the whole group's learning[3].

\section{Importance of case study in course teaching}

Improve self-learning ability

Traditional teaching method, characterized in dominated speaking and teaching by teachers. Students were passive receiver, not active participants in class, resulting in lower learning initiative, less thinking and feedback. Classroom teaching is made up of teaching and learning. It is a bilateral activity that teachers and students must join in together. It's form isn't monologue but dialogue. As a comprehensive course, course content is hard to understand just by traditional lecture. By using case study, the boring theory can be translated in real case. Student becomes active learner to understand theory and apply to the real practice, which can help student to form self-learning habit, therefore to improve the self-learning ability.

\section{Improve communication and cooperation ability}

Group discussion is usually used in case study. Students will be classed into groups, each member will have their own voice to form a group idea. And different groups will also have discussions to form a final idea. Everyone is active in the discussion. The case is studied and the issue is solved during the discussion. This will improve the ability in communication, cooperation and team work.

\section{Enhance issue analysis and solving ability}

Case study will also enhance the ability in issue analysis and solving, through real or simulated case. In case study, student is put into the practice situation. Student is required to apply basic theory to practice to find and solve the real problem, based on case information. Therefore, both the theory comprehension and issue solve ability are enhanced[4].

\section{Using of case method in auto marketing teaching}

\section{Drawing out the guidance role of teacher}

Teacher should become the guider of heuristics and participant in discussion, instead of theory instructor in traditional method. Students should be the major player in teaching, under the guidance of teacher. Case method induces higher requirement for teachers in both adequate theoretical and practical knowledge.

Good command of class teaching is also required. Teachers should be good at establish the atmosphere of freely discussion, and guide to deep discussion. When using case method, teacher should handle the conclusion of the students carefully. If agree what they think, teacher should tell them why. If disagree, teacher should put adequate reasonable explanation to make the students full understanding.

\section{Drawing out the main role of students}

Case method is a process, in which teacher acts as a guide, students keep on answering and responding, to find out the possible ways to solve a problem, either imaging or real. Therefore, students should play the main role in case teaching. Teacher should always try to arouse and protect the positivity of students. Whatever kind of case the teacher use, student in auto marketing should always be the main participant.

All kinds of method should be used in teaching to increase the interest of student, impelling students to find the solution. Teacher should make certain collection between in-class behavior of students and the final score. The majority of students should be included in stating, answering and discussion to enhance the command of what they have learned. Furthermore, the personality of individual student should be taking into consideration.

\section{Establish discussion based teaching atmosphere}

Teacher should do certain survey to understand the background and study situation of students, 
thus to using different teaching method for different students. Based on this, certain cases should be selected to using in class teaching, especially classic and latest auto insurance and claim related cases. When case is fixed, teacher should begin to design problems, make students truly getting into the problems and discuss about the problems. Teachers should keep on guiding when students are in discussion, to maintain the correct direction. Only when students truly adopting in discussion, can the main and positive role of students be established. After discussion, certain explanation and correction from teacher should be given to ensure the correct thinking method and solution of students. Therefore, the discussion based teaching atmosphere can be established, to give truly propelling for the teaching results.

\section{Using operable cases}

Cases are using to design certain problems based on the teaching aim. As a market oriented course, operable cases are vital to the teaching. Generally, the case should be practical happen issues, experiencing or described by others. Adequate data should be included in the case, to provide enough support for the solution of problems. If something important is missing, it is hard to get the correct conclusion and solution, which is harmful to the discussion process.

Operable case should be medium in length, not too long or too short, to maintain its heuristics. Operable case should include certain problem, which can arouse the thinking of students. Interesting problems are vital, in which students can find out several different paths, based on discussion, thinking and solving. The more thinking space the problem has, the better the teaching result is. Operable case should also include latest auto insurance and claim development, to closely collect to the real word. Furthermore, the case should be improved along with time, to provide perfect practice for class teaching [5].

Good case is the foundation for auto insurance course teaching. A high quality case either from the court decision or case with social focus, should have the following characters.

1)Pertinence: Case used in class discussion should be full of knowledge points, with strong pertinence. Case selection should be under the guidance of course target and teaching content. Pertinent case should be selected consistent with knowledge point, to enhance the comprehension for specific hard key points, thus to improve the ability to apply theory in practice.

2)Inspiration: Good case should incorporate certain problem, to inspire their thought. The more the problem probed into, the wider space for student to think. Therefore, the teaching effect will be better. It should be aware that the case should not move far away from the subject, just pure for inspiration.

3)Representativeness: Auto insurance case should be typical case which indicate insurance related theory, insurance law and real life law related law. These cases should have strong representativeness. Student can learn the basic auto insurance and related law, through case analysis. The case study can also enhance the comprehension of key points in course[5].

\section{Market Oriented Teaching}

The purpose for this course is to develop the ability of Auto Insurance knowledge and skill for future career. Therefore, teaching should be closely connected to market development. Beside the basic theory and structure, efforts should be put on market requirement. The teaching should emphasized on ability cultivation to meet the market requirement. The teaching should include the auto insurance practice process, which includes application, testing and verifying, technical checking, evaluation, and report submission. Thus, reporting ability should be included in the course. After basic theory teaching, case, video material and experiments should be included to force student to think and discuss in groups, with the summary and guidance of teachers, thus to improve their actual market ability.

\section{Emphasizing on practice and students' ability improvement}

The purpose for this course is to develop the ability of auto insurance ability, thus the practical technical process should be included, such as auto damage evaluation, technical status and overall performance checking, loss and assessment, and so on. There are three major knowledge modules including in auto insurance, which requires a lot of practice to make them qualified to the market. 
By using all kinds of practical teaching methods, experimental teaching, on-site demonstration and case study to visualize their basic theory base on practice, therefore cultivate their actual practice ability on auto insurance and claim.

Based on current market status, practical cases study should be emphasized. Most of the time, cases in the textbook cannot meet the requirement both in quantity and timing. Teach should gather more actual case, divide student into groups to discuss and analyze. In this kind of case study, student can not only understand the market, but also increase their learning interest thus to improve their analyzing ability for the future work[6].

\section{Conclusion}

As a practice-oriented course, strong collection between theory and practice teaching is required for this course. Case method is a very important method to improve the interest of students, and integrate theory and practice. Case method is a useful way to improve the ability of utilizing knowledge to solve actual problem, and enhance the career competence and ability. Teachers should keep on learning to improve teaching ability, using case method teaching to become a effective method for Auto Insurance course teaching.

\section{Acknowledgement}

This work is sponsored by course developing project on Auto Insurance and Claim Course (k201206004) and Platform Developing Project of Modern Auto Service Engineering Major (XKCZ1214 ) in Shanghai University of Engineering Science.

\section{References}

[1] Jenny Lai and Hussain Ahmad. "Auto Insurance picks up speed in China," Emphasis,2007,3:2-5.

[2] Chen Qin. “Application of CaseMethod in the Auto Insurance Teaching,” Journal of Guangdong Industry Technical College, 2007,6(4):36-39.

[3] Robinson, Marc. “How to write a case study,” William Davidson Institute note 1-429-140, Rev. October 10, 2010

[4] F.M. Guan, C.W. Zheng. "Course development and teaching reform based on process for automotive marketing major,” Teaching Research, 2010,2:15-18

[5] Dong E.G, Zhang L., Guan Z.W., et al. "Reform and practice of Auto Insurance and Claim Course,” Specialized Education Research, 2010,11:82-83.

[6] Song X.Q. "Research on the teaching mode of Auto Insurance and Claim Course in college," Educaiton and Teaching, 2011,12:94-95. 